\title{
STRATEGI PENGEMBANGAN AYAM SENTUL DI KABUPATEN CIAMIS
}

\author{
AGUS YUNIAWAN ISYANTO \\ Fakultas Pertanian Universitas Galuh \\ Email: gus_yun69@yahoo.co.id \\ SUDRAJAT \\ Fakultas Pertanian Universitas Galuh \\ Email: sudradjat@unigal.ac.id \\ MOHAMAD ISKANDAR \\ Badan Perencanaan Pembangunan Daerah Kabupaten Ciamis \\ Email: Izdik@yahoo.com
}

\begin{abstract}
Abstrak
Penelitian ini dilaksanakan dengan tujuan untuk merumuskan strategi pengembangan ayam Sentul di Kabupaten Ciamis. Penelitian dilaksanakan dengan menggunakan metode survai. Penelitian dilaksanakan pada pada bulan September sampai dengan Oktober 2015. Responden terdiri atas: (1) Peternak ayam Sentul sebanyak 36 orang, dan (2) Responden lainnya, yaitu pegawai dinas/instansi pemerintah dan akademisi sebanyak 8 orang. Data penelitian terdiri atas data primer dan data sekunder. Strategi pengembangan ayam Sentul di Kabupaten Ciamis dirumuskan dengan menggunakan analisis SWOT.

Hasil penelitian menunjukkan bahwa strategi pengembangan ayam Sentul di Kabupaten Ciamis adalah: (1) Meningkatkan supply day old chick (DOC) untuk memenuhi kebutuhan peternak, (2) Meningkatkan penawaran melalui peningkatan populasi ayam Sentul untuk memenuhi permintaan konsumen terhadap daging ayam, (3) Pembuatan sentra produksi ayam Sentul untuk mengantisipasi tarik menarik kepentngan penggunaan lahan antara budidaya ayam Sentul dengan pemukiman serta untuk memudahkan di dalam monitoring kesehatan ayam Sentul, (4) Peningkatan jumlah kepemilikan ayam Sentul per peternak melalui skema kredit program dengan penekanan pada kegiatan monitoring dan evaluasi agar tepat pada tujuan dan sasaran, (5) Peningkatan kemampuan teknis peternak dalam memelihara ayam Sentul melalui kegiatan penyuluhan, pelatihan maupun bimbingan teknis untuk meningkatkan produktivitas, (6) Peningkatan efisiensi dan produktivitas melalui kebijakan produksi yang didukung dengan koordinasi lintas sektoral yang baik, (7) Pemberian subsidi produksi untuk menjamin kelangsungan produksi agar tidak terpengaruh secara signifikan oleh fluktuasi harga sarana produksi, dan (8) Peningkatan kemampuan manajemen peternak dalam hal kesehatan ayam Sentul melalui kegiatan penyuluhan, pelatihan maupun bimbingan teknis untuk mendukung tercapainya efisiensi dan produktivitas yang tinggi.
\end{abstract}

Kata kunci: Ayam Sentul, Strategi, Pengembangan

\begin{abstract}
This research was conducted with the aim to formulate Sentul chicken development strategies in Ciamis. The research was conducted using the survey method. Research was conducted in September and October 2015. Respondents consisted of: (1) Breeders chicken Sentul many as 36 people, and (2) Other respondents, namely civil servants / government agencies and academia as many as 8 people. The research data consist of primary data and secondary data. Sentul chicken development strategy in Ciamis formulated using SWOT analysis.
\end{abstract}


The results showed that the chicken Sentul development strategy in Ciamis are: (1) Increasing the supply of day old chick (DOC) to meet the needs of farmers, (2) Increase the supply through the improvement of the chicken population Sentul to meet consumer demand for chicken meat, (3) Making the chicken Sentul production centers to anticipate conflict of interest about land using between chicken Sentul farming Sentul and settlement as, also easily to facilitate in monitoring the health of chickens Sentul, (4) The increase in the number of holdings chicken Sentul per farmer via credit scheme program with an emphasis on monitoring and evaluation in order to right on the goals and objectives, (5) Improved technical capacity of farmers in raising chickens Sentul through extension activities, training and technical assistance to improve productivity, (6) Increased efficiency and productivity through production policies are supported by cross-sectoral coordination is good, (7) Production subsidies to ensure continuity of production that is not significantly affected by fluctuations in the price of the means of production, and (8) Improved management capabilities of Sentul chicken farmers in health through counseling activities, training and technical assistance to support the achievement of efficiency and high productivity.

Keywords: Sentul chicken, Strategy, Development

\section{PENDAHULUAN}

Produktivitas ayam buras umumnya masih rendah (Suryana dan Hasbianto, 2008), namun tidak menurunkan minat dari masyarakat untuk membudidayakannya karena, antara lain ciri khas daging ayam lokal yang gurih menyebabkan permintaan pasar meningkat (Daryono, dkk., 2012). Selain itu, telur dan dagingnya lebih mahal harganya dan memiliki preferensi lebih baik dibandingkan ayam ras (Depirson, 2009). Namun demikian, usaha pengembangan ayam lokal sekarang ini masih mengalami hambatan yang disebabkan oleh kurangnya tata laksana pemeliharaan, baik segi makanan, kandang maupun kesehatan ayam (Alam, 2005). Salah satu jenis ayam lokal di Indonesia adalah ayam Sentul yang telah diakui sebagai plasma nutfah Kabupaten Ciamis melalui SK Menteri Pertanian RI No. 689/Kpts.PD410/2/2013 tentang Penetapan Rumpun Ayam Sentul Sebagai Ayam Rumpun Lokal Indonesia Asal Ciamis.

Ayam Sentul merupakan ayam lokal yang mempunyai potensi cukup tinggi sebagai ternak penghasil telur dan daging (Sartika, 2010). Bobot badan ayam Sentul pada umur 20 minggu dapat mencapai $2,20 \mathrm{~kg}$ bila dipelihara secara intensif (Kurnia, 2011 dalam Meyliyana, dkk., 2013). Ayam Sentul mampu bertelur sampai 26 butir per periode bertelur (Nataamijaya, 2005), atau sekitar 150 butir/tahun (Baktiningsih, dkk. 2013).

Populasi ayam Sentul saat ini sekitar 30.000 ekor dan cenderung 
menurun karena adanya peningkatan permintaan daging (Hartono, dkk., 2013; Baktiningsih, dkk., 2013). Melihat fakta tersebut, maka upaya pengembangan ayam Sentul ini perlu dilakukan selain untuk menjaga kelestarian ayam Sentul, juga untuk memenuhi permintaan pasar. Populasi ayam Sentul yang tinggal sedikit menuntut upaya pengembangan lebih lanjut ke depan. Di samping untuk melestarikan plasma nutfah asli Indonesia, juga untuk memaksimalkan manfaat yang dapat digali dari potensi genetik yang dimilikinya (Hidayat dan Sopiyana, 2010).

Berdasarkan uraian di atas, maka tujuan penelitian ini adalah untuk merumuskan strategi pengembangan ayam Sentul di Kabupaten Ciamis.

\section{TINJAUAN PUSTAKA}

\section{Karakteristik Ayam Sentul}

Penampilan fisik ayam Sentul tergolong tipe aduan, tetapi kini dipelihara sebagai penghasil daging dan telur. Sifat-sifat yang baik dari ayam Sentul, yaitu pertumbuhan yang lebih cepat, lebih tahan terhadap penyakit, dan produksi telur relatif lebih tinggi dibandingkan ayam buras lainnya, yaitu satu periode peneluran dihasilkan 10-18 butir per periode peneluran dengan fertilitas di atas $80 \%$ dan, daya tetas tinggi yaitu 70-80 \% (Widjastuti, 2009).

Ayam Sentul memiliki lima jenis yang berbeda yaitu ayam Sentul Abu, Sentul Batu, Sentul Debu, Sentul Geni dan Sentul Emas. Masing-masing jenis ayam Sentul pasti memiliki potensi yang berbeda berdasarkan genetik yang diperoleh dari masing-masing induknya. Salah satu performans produksi yang kemungkinan berbeda adalah produksi telur individu yang meliputi jumlah telur dan dari catatan produksi telur, hen day production (HDP) dan hen house production (HHP) (Baktiningsih, dkk., 2013).

Rataan bobot badan ayam Sentul (Batu, Abu, Debu, Emas dan Geni) umur 2 bulan jantan adalah 628.06 \pm 22.16 , $611.74 \pm 35.69, \quad 605.38 \pm 45.71, \quad 636.61 \pm$ 49.63 , dan $618.70 \pm 43.85$, betina $601.04 \pm$ $32.21, \quad 614.35 \pm 26.06, \quad 611.69 \pm 57.70$, 610.76 \pm 61.68 , dan 628.71 \pm 12.08 . Ayam Sentul umur 5 bulan jantan adalah $1768,19 \pm 50,82,1812,03 \pm 37,96,1768,34$

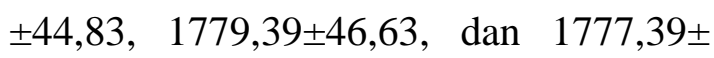
40,62 , betina $1287,11 \pm 24,47,1300,55 \pm$ $13,19, \quad 1286,21 \pm 36,59, \quad 1284,43 \pm 28,85$, dan $1287,06 \pm 24,21$. Ayam Sentul dewasa jantan adalah 2736,23 $\pm 140,45$, $2817,74 \pm 106,19, \quad 2751,81 \pm 73,49$, $2693,11 \pm 142,18$, dan 2781,86 $\pm 82,91$, 
betina $1690,06 \pm 62,78,1713,57 \pm 125,88$, $1745,43 \pm 65,44, \quad 1714,09 \pm 131,43, \quad$ dan

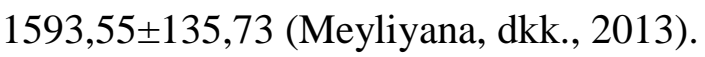

\section{Analisis SWOT}

Analisis SWOT adalah identifikasi berbagai faktor secara sistematis untuk merumuskan strategi perusahaan. Analisis ini didasarkan pada logika yang dapat memaksimalkan kekuatan (Strengths) dan peluang (Opportunities), namun secara bersamaan dapat meminimalkan kelemahan (Weakness) dan ancaman (Threats). Proses pengambilan keputusan strategis selalu berkaitan dengan pengembangan misi, tujuan, strategi, dan kebijakan perusahaan. Dengan demikian perencana strategis (Strategic planner) harus menganalisis faktor-faktor strategis perusahaan (kekuatan, kelemahan, peluang dan ancaman) dalam kondisi yang ada saat ini. Hal ini disebut dengan Analisis Situasi. Model yang paling populer untuk analisis situasi adalah Analisis SWOT (Rangkuti, 2003).

\section{METODE PENELITIAN}

Penelitian dilaksanakan dengan menggunakan metode survai. Menurut Singarimbun (1989), penelitian survai adalah penelitian yang mengambil sampel dari satu populasi dan menggunakan kuesioner sebagai alat pengumpulan data yang pokok.

Penelitian dilaksanakan pada pada bulan September sampai dengan Oktober 2015. Responden terdiri atas:

Peternak ayam Sentul sebanyak 36 orang, dan (2) Responden lainnya, yaitu pegawai dinas/instansi pemerintah dan akademisi sebanyak 8 orang.

Data penelitian terdiri atas data primer yang diperoleh melalui wawancara responden dengan menggunakan kuesioner yang telah dipersiapkan sebelumnya, dan data sekunder yang diperoleh melalui penelusuran pustaka atau referensi, maupun data yang diperoleh dari dinas atau instansi terkait.

Strategi pengembangan ayam Sentul di Kabupaten Ciamis dirumuskan dengan menggunakan analisis SWOT.

\section{HASIL DAN PEMBAHASAN}

\section{A. FAKTOR INTERNAL}

\section{(1) Identifikasi Kekuatan dan}

\section{Kelemahan Internal}

Identifikasi faktor strategi internal berupa kekuatan dan kelemahan yang berpengaruh terhadap keberhasilan pengembangan ayam Sentul di Kabupaten Ciamis sebagaimaa terlihat pada Tabel 1. 
Jurnal Pemikiran Masyarakat Ilmiah Berwawasan Agribisnis. 2017. 3(1): 1-12

Tabel 1. Kekuatan dan Kelemahan Internal

\begin{tabular}{|c|c|c|c|}
\hline No & Kekuatan (Strenghts) & No & Kelemahan (Weakness) \\
\hline 1 & $\begin{array}{l}\text { Iklim dan kondisi alam sesuai } \\
\text { untuk budidaya ayam Sentul }\end{array}$ & 1 & $\begin{array}{l}\text { Usaha ayam Sentul masih sebagai usaha } \\
\text { sampingan }\end{array}$ \\
\hline 2 & $\begin{array}{l}\text { Tingginya motivasi peternak } \\
\text { ayam Sentul }\end{array}$ & 2 & $\begin{array}{l}\text { Kepemilikan ayam Sentul per peternak } \\
\text { masih rendah }\end{array}$ \\
\hline 3 & $\begin{array}{l}\text { Pengalaman peternak relatif } \\
\text { baik }\end{array}$ & $\begin{array}{l}3 \\
4\end{array}$ & $\begin{array}{l}\text { Pendidikan peternak relatif rendah } \\
\text { Pengetahuan dan keterampilan teknis }\end{array}$ \\
\hline 4 & $\begin{array}{l}\text { Ketersediaan lahan untuk } \\
\text { pengembangan }\end{array}$ & 5 & $\begin{array}{l}\text { relatif rendah } \\
\text { Modal relatif rendah }\end{array}$ \\
\hline 5 & Pasar masih terbuka luas & 6 & Minimnya informasi pemasaran \\
\hline 6 & $\begin{array}{l}\text { Tersedianya sarana } \\
\text { transportasi yang memadai }\end{array}$ & $\begin{array}{l}7 \\
8\end{array}$ & $\begin{array}{l}\text { Teknologi budidaya masih rendah } \\
\text { Koordinasi lintas sektoral masih rendah }\end{array}$ \\
\hline 7 & $\begin{array}{l}\text { Adanya kelompok peternak } \\
\text { ayam Sentul }\end{array}$ & $\begin{array}{c}9 \\
10\end{array}$ & $\begin{array}{l}\text { Pasokan DOC masih kurang } \\
\text { Data produksi dan konsumsi belum }\end{array}$ \\
\hline 8 & $\begin{array}{l}\text { Adanya kawasan ternak ayam } \\
\text { Sentul }\end{array}$ & $\begin{array}{l}11 \\
12\end{array}$ & $\begin{array}{l}\text { akurat } \\
\text { Pembinaan kelompok belum intensif } \\
\text { Peternak belum memahami potensi } \\
\text { genetis }\end{array}$ \\
\hline
\end{tabular}

(2) Evaluasi Faktor Lingkungan Internal

Tahap ini merupakan tahap lanjutan setelah identifikasi faktor lingkungan internal berupa penyusunan matriks IFAS (Internal Factor Analysis Summary) untuk mendapatkan nilai skor. Nilai skor tersebut merupakan hasil penjumlahan total dari hasil perkalian bobot dengan rating masing-masing indikator faktor strategis internal. Pembobotan dilakukan dengan mengklasifikasikan setiap indikator sesuai dengan kepentingan atau rating, sehingga dapat diperoleh bobot dari masing-masing indikator strategis internal (kekuatan dan kelemahan). Matriks IFAS dapat dilihat pada Tabel 2.

Total skor yang diperoleh pada Matriks IFAS sebesar 9,52 yang menunjukkan bahwa faktor lingkungan internal berada pada tingkat kepentingan baik. Kondisi tersebut menggambarkan bahwa pengembangan ayam Sentul di Kabupaten Ciamis dapat mengendalikan faktor lingkungan internalnya (kekuatan dan kelemahan) serta dapat menunjang dalam pengembangannya. 
Tabel 2. Matriks IFAS (Internal Factors Analysis Summary)

\begin{tabular}{clccc}
\hline No & Faktor Internal & Bobot & Rating & Skor \\
\cline { 2 - 3 } 1 & Kekuatan (Strenghts) & & & \\
& Iklim dan kondisi alam sesuai untuk budidaya ayam & & & \\
2 & Sentul & 0,12 & 5 & 0.57 \\
3 & Tingginya motivasi peternak ayam Sentul & 0,13 & 5 & 0.60 \\
4 & Kengalaman peternak relatif baik & 0,13 & 5 & 0.59 \\
5 & Pasar masih terbuka luas & 0,13 & 5 & 0.63 \\
6 & Tersedianya sarana transportasi yang memadai & 0,13 & 5 & 0.64 \\
7 & Adanya kelompok peternak ayam Sentul & 0,13 & 5 & 0.60 \\
8 & Adanya kawasan ternak ayam Sentul & 0,13 & 5 & 0.63 \\
\hline & Sub Total & 0,13 & 5 & 0.63 \\
\hline No & Kelemahan (Weaknesses) & 1,02 & & 4,88 \\
\hline 1 & Usaha ayam Sentul masih sebagai usaha sampingan & 0,08 & 4 & 0,34 \\
2 & Kepemilikan ayam Sentul per peternak masih rendah & 0,08 & 4 & 0,37 \\
3 & Pendidikan peternak relatif rendah & 0,09 & 4 & 0,38 \\
4 & Pengetahuan dan keterampilan teknis relatif rendah & 0,09 & 5 & 0,40 \\
5 & Modal relatif rendah & 0,09 & 5 & 0,39 \\
6 & Minimnya informasi pemasaran & 0,08 & 4 & 0,37 \\
7 & Teknologi budidaya masih rendah & 0,09 & 5 & 0,40 \\
8 & Koordinasi lintas sektoral masih rendah & 0,08 & 4 & 0,37 \\
9 & Pasokan DOC masih kurang & 0,09 & 5 & 0,43 \\
10 & Data produksi dan konsumsi belum akurat & 0,09 & 5 & 0,39 \\
11 & Pembinaan kelompok belum intensif & 0,09 & 5 & 0,39 \\
12 & Peternak belum memahami potensi genetis & 0,09 & 5 & 0,41 \\
\hline & Sub Total & 1,03 & & 4,64 \\
\hline & Total & 2,05 & & 9,52 \\
\hline
\end{tabular}

\section{B. FAKTOR EKSTERNAL}

\section{(1) Identifikasi Peluang dan Ancaman}

Faktor strategis eksternal meliputi faktor peluang dan ancaman. Identifikasi faktor-faktor peluang dan ancaman ini dilakukan untuk mengidentifikasi faktor peluang dan ancaman yang berpengaruh terhadap keberlangsungan pengembangan ayam Sentul di Kabupaten Ciamis. Faktor-faktor peluang dan ancaman eksternal yang dapat diidentifikasi dapat dilihat pada Tabel 3. 
Jurnal Pemikiran Masyarakat Ilmiah Berwawasan Agribisnis. 2017. 3(1): 1-12

Tabel 3. Peluang dan Ancaman Eksternal

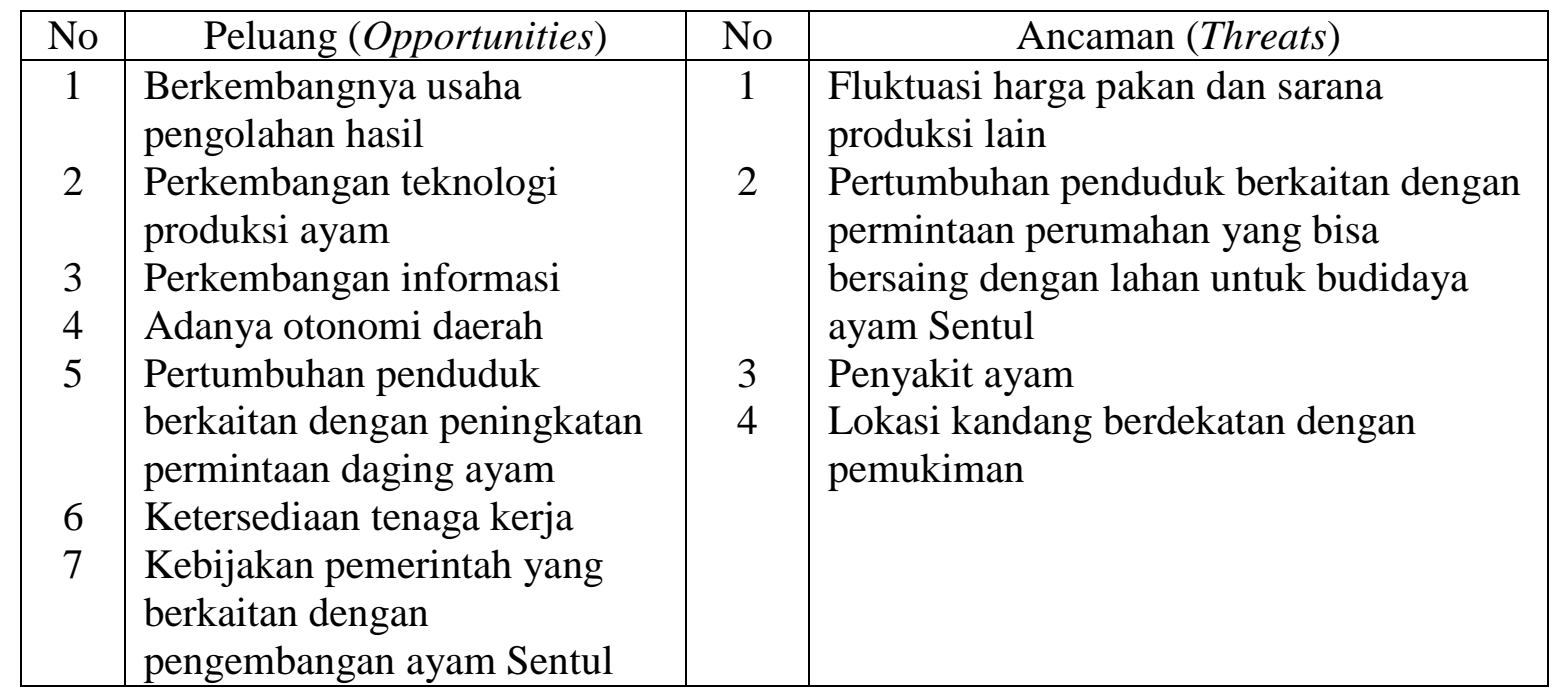

(2) Evaluasi Faktor Lingkungan Eksternal

Evaluasi faktor lingkungan
Matriks EFAS sebagaimana terlihat pada

Tabel 4. Total skor yang diperoleh pada Matriks EFAS sebesar 9,24.

eksternal dilakukan dengan menggunakan

Tabel 4. Matriks EFAS (Eexternal Factors Analysis Summary)

\begin{tabular}{clccc}
\hline No & Faktor Internal & Bobot & Rating & Skor \\
\cline { 2 - 3 } 1 & Peluang (Opportunities) & & & \\
2 & Berkembangnya usaha pengolahan hasil & 0.14 & 4 & 0.64 \\
3 & Perkembangan teknologi produksi ayam & 0.15 & 5 & 0.67 \\
4 & Perkembangan informasi & 0.14 & 5 & 0.66 \\
5 & Adanya otonomi daerah & 0.14 & 4 & 0.63 \\
& Pertumbuhan penduduk berkaitan dengan & & & \\
6 & peningkatan permintaan daging ayam & 0.15 & 5 & 0.66 \\
7 & Ketersediaan tenaga kerja & 0.15 & 5 & 0.66 \\
& pengembangan ayam Sentul & & & \\
& Sub Total & 0.15 & 5 & 0.73 \\
\hline No & Ancaman (Threat) & 1,02 & & 4,65 \\
\hline 1 & Fluktuasi harga pakan dan sarana produksi lain & 0.25 & 4 & 1.13 \\
2 & Pertumbuhan penduduk berkaitan dengan permintaan & & & \\
& perumahan & 0.24 & 4 & 1.06 \\
3 & Penyakit ayam & 0.26 & 5 & 1.21 \\
4 & Lokasi kandang berdekatan dengan pemukiman & 0.26 & 5 & 1.18 \\
\hline & Sub Total & 1,01 & & 4,58 \\
\hline & Total & 2,03 & & 9,24 \\
\hline
\end{tabular}




\section{ANALISIS SWOT}

Berdasarkan aspek kekuatan, kelemahan, peluang, dan ancaman, maka dapat disusun beberapa alternatif strategi pengembangan usaha ayam Sentul di Kabupaten Ciamis. Aspek-aspek internal dan eksternal dikombinasikan dan disusun dalam matriks SWOT yang dapat menggambarkan secara jelas bagaimana peluang dan ancaman eksternal yang dihadapi dapat disesuaikan dengan kekuatan dan kelemahan yang dimilikinya. Matriks SWOT dapat dilihat pada Tabel 5.

Tabel 5. Strategi Pengembangan Ayam Sentul di Kabupaten Ciamis

\begin{tabular}{|c|c|c|}
\hline FAKTOR INTERNAL & $\begin{array}{l}\text { KEKUATAN (S) } \\
\text { 1. Iklim dan kondisi alam sesuai } \\
\text { untuk budidaya ayam Sentul } \\
\text { 2. Tingginya motivasi peternak } \\
\text { ayam Sentul } \\
\text { 3. Pengalaman peternak relatif } \\
\text { baik } \\
\text { 4. Ketersediaan lahan untuk } \\
\text { pengembangan } \\
\text { 5. Pasar masih terbuka luas } \\
\text { 6. Tersedianya sarana transportasi } \\
\text { yang memadai } \\
\text { 7. Adanya kelompok peternak } \\
\text { ayam Sentul } \\
\text { 8. Adanya kawasan ternak ayam } \\
\text { Sentul }\end{array}$ & $\begin{array}{l}\text { KELEMAHAN (W) } \\
\text { 1. Usaha ayam Sentul masih sebagai } \\
\text { usaha sampingan } \\
\text { 2. Kepemilikan ayam Sentul per } \\
\text { peternak masih rendah } \\
\text { 3. Pendidikan peternak relatif rendah } \\
\text { 4. Pengetahuan dan keterampilan } \\
\text { teknis relatif rendah } \\
\text { 5. Modal relatif rendah } \\
\text { 6. Minimnya informasi pemasaran } \\
\text { 7. Teknologi budidaya masih rendah } \\
\text { 8. Koordinasi lintas sektoral masih } \\
\text { rendah } \\
\text { 9. Pasokan DOC masih kurang } \\
\text { 10. Data produksi dan konsumsi belum } \\
\text { akurat } \\
\text { 11. Pembinaan kelompok belum } \\
\text { intensif } \\
\text { 12. Peternak belum memahami potensi } \\
\text { genetis }\end{array}$ \\
\hline $\begin{array}{l}\text { PELUANG (O) } \\
\text { 1. Berkembangnya usaha } \\
\text { pengolahan hasil } \\
\text { 2. Perkembangan teknologi } \\
\text { produksi ayam } \\
\text { 3. Perkembangan informasi } \\
\text { 4. Adanya otonomi daerah } \\
\text { 5. Pertumbuhan penduduk } \\
\text { berkaitan dengan } \\
\text { peningkatan permintaan } \\
\text { daging ayam } \\
\text { 6. Ketersediaan tenaga kerja } \\
\text { 7. Kebijakan pemerintah yang } \\
\text { berkaitan dengan } \\
\text { pengembangan ayam Sentul }\end{array}$ & \begin{tabular}{l}
\multicolumn{1}{c}{ STRATEGI S-O } \\
1. \\
Meningkatkan supply DOC \\
untuk memenuhi kebutuhan \\
peternak (S2,S3,S5,S7- \\
O1,O2,O5,O6,O7) \\
2. Meningkatkan penawaran \\
melalui peningkatan populasi \\
ayam Sentul untuk memenuhi \\
permintaan konsumen terhadap \\
daging ayam \\
(S1,S4,S5,S6,S7,S8- \\
O1,O2,O3,O5,O6,O7)
\end{tabular} & $\begin{array}{l}\text { STRATEGI W-O } \\
\text { 1. Peningkatan jumlah kepemilikan } \\
\text { ayam Sentul per peternak melalui } \\
\text { skema kredit program dengan } \\
\text { penekanan pada kegiatan } \\
\text { monitoring dan evaluasi agar tepat } \\
\text { pada tujuan dan sasaran (W2,W5,- } \\
\text { O1,O4,O5,O7) } \\
\text { 2. Peningkatan kemampuan teknis } \\
\text { peternak dalam memelihara ayam } \\
\text { Sentul melalui kegiatan } \\
\text { penyuluhan, pelatihan maupun } \\
\text { bimbingan teknis untuk } \\
\text { meningkatkan produktivitas } \\
\text { (W1,W2,W3-O2,O3,O4,O5) } \\
\text { Peningkatan efisiensi dan } \\
\text { produktivitas melalui kebijakan } \\
\text { produksi yang didukung dengan } \\
\text { koordinasi lintas sektoral yang baik } \\
\text { (W8,W10,W11,W12- } \\
\text { O2,O3,O4,O5,O7) }\end{array}$ \\
\hline
\end{tabular}




\begin{tabular}{|c|c|c|}
\hline $\begin{array}{l}\text { ANCAMAN }(\mathrm{T}) \\
\text { 1. Fluktuasi harga pakan dan } \\
\text { sarana produksi lain } \\
\text { 2. Pertumbuhan penduduk } \\
\text { berkaitan dengan permintaan } \\
\text { perumahan yang bisa } \\
\text { bersaing dengan lahan untuk } \\
\text { budidaya ayam Sentul } \\
\text { 3. Penyakit ayam } \\
\text { 4. Lokasi kandang berdekatan } \\
\text { dengan pemukiman }\end{array}$ & \begin{tabular}{l}
\multicolumn{1}{c}{ STRATEGI S-T } \\
1. Pembuatan sentra produksi \\
ayam Sentul untuk \\
mengantisipasi tarik menarik \\
kepentngan penggunaan lahan \\
antara budidaya ayam Sentul \\
dengan pemukiman serta untuk \\
memudahkan di dalam \\
monitoring kesehatan ayam \\
Sentul (S1,S4,S7,S8-O3,04)
\end{tabular} & \begin{tabular}{l}
\multicolumn{1}{c}{ STRATEGI W-T } \\
1. Pemberian subsidi produksi untuk \\
menjamin kelangsungan produksi \\
agar tidak terpengaruh secara \\
signifikan oleh fluktuasi harga \\
sarana produksi \\
(S2,S3,S4,S5,S7,S8-T1,T2) \\
2. Peningkatan kemampuan \\
manajemen peternak dalam hal \\
kesehatan ayam Sentul melalui \\
kegiatan penyuluhan, pelatihan \\
maupun bimbingan teknis untuk \\
mendukung tercapainya efisiensi \\
dan produktivitas yang tinggi \\
(S4,S7,S11-O2,03,04)
\end{tabular} \\
\hline
\end{tabular}

\section{(1) Strategi S - O}

a. Meningkatkan supply bibit ayam (Day Olcd Chicken, DOC) untuk memenuhi kebutuhan peternak.

Peningkatan supply DOC ini dapat dilakukan melalui usaha pembibitan yang dilakukan oleh peternak, kelompok ternak, gabungan kelompok ternak, maupun dinas/instansi.

b. Meningkatkan penawaran melalui peningkatan populasi ayam Sentul untuk memenuhi permintaan konsumen terhadap daging ayam

Peningkatan supply DOC akan meningkatkan jumlah populasi sehingga secara langsung akan meningkatkan penawaran produk yang dapat memenuhi kebutuhan konsumen.

\section{(2) Strategi W - O}

a. Peningkatan jumlah kepemilikan ayam Sentul per peternak melalui skema kredit program dengan penekanan pada kegiatan monitoring dan evaluasi agar tepat pada tujuan dan sasaran.

b. Peningkatan kemampuan teknis peternak dalam memelihara ayam Sentul melalui kegiatan penyuluhan, pelatihan maupun bimbingan teknis untuk meningkatkan produktivitas.

c. Peningkatan efisiensi dan produktivitas melalui kebijakan produksi yang didukung dengan koordinasi lintas sektoral yang baik.

\section{(3) Strategi $\mathbf{S}$ - T}

Pembuatan sentra produksi ayam Sentul untuk mengantisipasi tarik menarik kepentngan penggunaan lahan antara budidaya ayam Sentul dengan pemukiman serta untuk memudahkan di dalam monitoring kesehatan ayam Sentul

\section{(4) Strategi $W-T$}

a. Pemberian subsidi produksi untuk menjamin kelangsungan produksi agar 
tidak terpengaruh secara signifikan oleh fluktuasi harga sarana produksi

b. Peningkatan kemampuan manajemen peternak dalam hal kesehatan ayam
Sentul melalui kegiatan penyuluhan, pelatihan maupun bimbingan teknis untuk mendukung tercapainya efisiensi dan produktivitas yang tinggi.

Tabel 6. Perhitungan Nilai Skor terhadap Alternatif Strategi

\begin{tabular}{|c|c|c|}
\hline IFAS & $\begin{array}{c}\text { Strength }(\mathrm{S}) \\
\text { Kekuatan }\end{array}$ & $\begin{array}{c}\text { Weaknesees }(\mathrm{W}) \\
\text { Kelemahan }\end{array}$ \\
\hline Opportunites $(\mathrm{O})$ & Strategi S-O & Strategi W-O \\
Peluang & $4,88+4,65=9,53$ & $4,64+4,65=9,29$ \\
\hline Treaths $(\mathrm{T})$ & Strategi S-T & Strategi W-T \\
Ancaman & $4,88+4,58=9,45$ & $4,64+4,58=9,22$ \\
\hline
\end{tabular}

Perhitungan analisis Matriks SWOT memberikan altenatif strategi yang paling sesuai dengan keadaan faktor lingkungan internal dan eksternal yang dimiliki dalam pengembangan ayam Sentul di Kabupaten Ciamis yaitu strategi S-O dengan skor alternatif strategis sebesar 9,53.

Cara untuk melihat peta kekuatan atau eksistensi posisi saat ini selain dengan matriks SWOT dapat dilihat pula dalam matriks kuadran. Berdasarkan hasil perhitungan diperoleh nilai IFAS sebesar 9,52 dengan nilai faktor kekuatan sebesar 4,88 dan nilai faktor kelemahan sebesar 4,64, sehingga diperoleh selisih sebesar 0,24 . Nilai EFAS sebesar 9,24 dengan nilai faktor peluang sebesar 4,65 dan nilai faktor ancaman sebesar 4,58 sehingga diperoleh selisih sebesar 0,07. Hasil tersebut menunjukkan posisi pada Kuadran I yang berkorelasi positif dengan Matiks SWOT sebagaimana disajikan dalam Gambar 1.

Gambar 1 menunjukkan bahwa posisi pengembangan ayam Sentul di Kabupaten Ciamis berada dalam situasi yang sangat menguntungkan. Posisi tersebut memiliki peluang dan kekuatan yang ada untuk kemajuan kegiatan usaha. Strategi yang harus diterapkan dalam kondisi ini adalah mendukung kebijakan pertumbuhan yang agresif (Growth oriented strategy). 


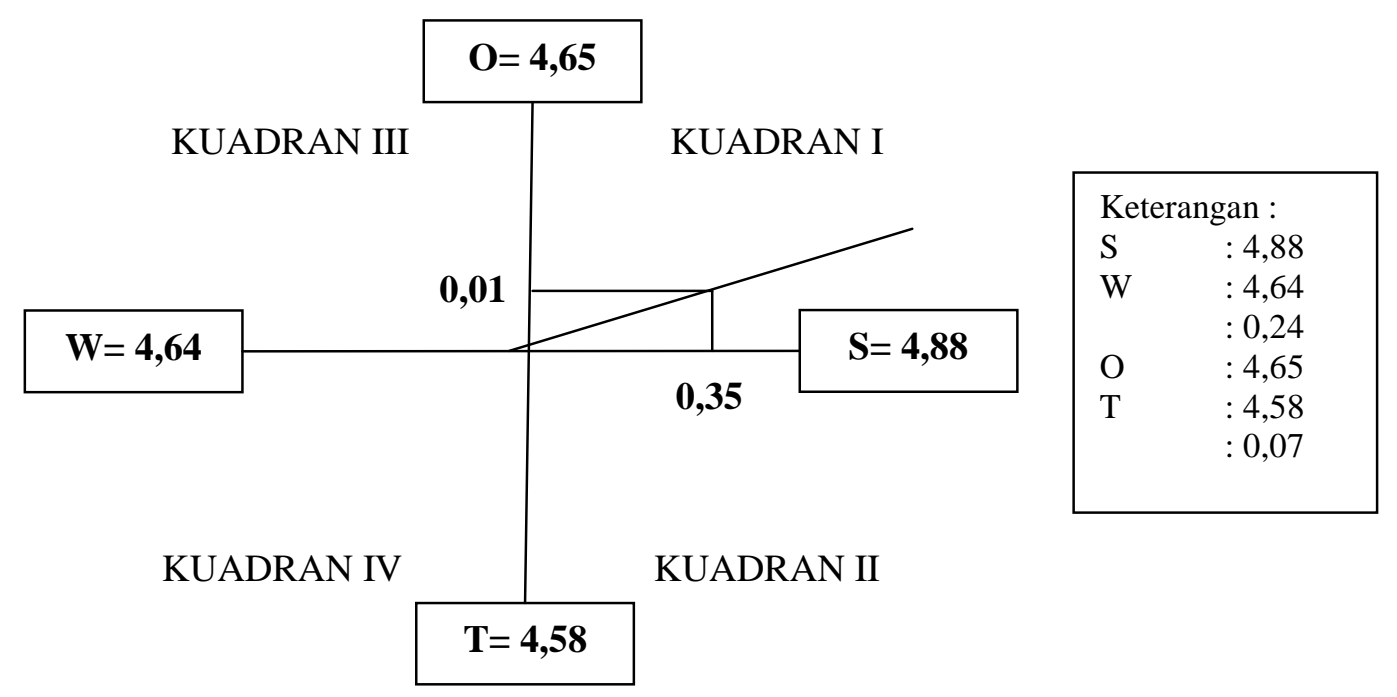

Gambar 1. Matriks Kuadran Pengembangan Ayam Sentul di Kabupaten Ciamis

\section{PENUTUP}

Strategi pengembangan ayam Sentul di Kabupaten Ciamis adalah: (1) Meningkatkan supply DOC untuk memenuhi kebutuhan peternak, (2) Meningkatkan penawaran melalui peningkatan populasi ayam Sentul untuk memenuhi permintaan konsumen terhadap daging ayam, (3) Pembuatan sentra produksi ayam Sentul untuk mengantisipasi tarik menarik kepentngan penggunaan lahan antara budidaya ayam Sentul dengan pemukiman serta untuk memudahkan di dalam monitoring kesehatan ayam Sentul, (4) Peningkatan jumlah kepemilikan ayam Sentul per peternak melalui skema kredit program dengan penekanan pada kegiatan monitoring dan evaluasi agar tepat pada tujuan dan sasaran, (5) Peningkatan kemampuan teknis peternak dalam memelihara ayam Sentul melalui kegiatan penyuluhan, pelatihan maupun bimbingan teknis untuk meningkatkan produktivitas, (6) Peningkatan efisiensi dan produktivitas melalui kebijakan produksi yang didukung dengan koordinasi lintas sektoral yang baik, (7) Pemberian subsidi produksi untuk menjamin kelangsungan produksi agar tidak terpengaruh secara signifikan oleh fluktuasi harga sarana produksi, dan (8) Peningkatan kemampuan manajemen peternak dalam hal kesehatan ayam Sentul melalui kegiatan penyuluhan, pelatihan maupun bimbingan teknis untuk mendukung tercapainya efisiensi dan produktivitas yang tinggi. 


\section{DAFTAR PUSTAKA}

Alam, H.I.P. 2005. Resistensi Ayam Lokal Jawa Barat: Ayam Sentul. Lokakarya Nasional Inovasi Teknologi Pengembangan Ayam Lokal. Puslitbangnak. Bogor.

Baktiningsih, S., Mugiyono, S., dan Saleh, D.M. 2013. Produksi Telur Berbagai Jenis Ayam Sentul di Gabungan Kelompok Tani Ternak Ciung Wanara Kecamatan Ciamis Kabupaten Ciamis. Jurnal Ilmiah Peternakan 1(3): 993-1000.

Daryono, B.S., Satriya, R., Rohmah, Z., dan Erwanto, Y. 2012. Penguatan Industri Bibit Unggas Nasional Melalui Produksi Indukan Gama Ayam Lokal Unggul. Jurnal Ilmu Pengetahuan dan Teknologi Tepat Guna Universitas Gadjah Mada 1(2): 95-103.

Depison. 2009. Karakteristik Kuantitatif dan Kualitatif Hasil Persilangan Beberapa Ayam Lokal. Jurnal Ilmiah Ilmu-Ilmu Peternakan XII(1): 7-13.

Hartono, E.H., Hidayat, N.N., dan Roesdiyanto. 2013. Kinerja Ekonomi Usaha Ayam Sentul di Kabupaten Ciamis. Jurnal Ilmiah Peternakan 1(3): 865-873.

Hidayat, C., dan Sopiyana, S. 2010. Potensi Ayam Sentul Sebagai Plasma Nutfah Asli Ciamis Jawa Barat. Wartazoa 20(4): 190-205.

Mariandayani, H.N., Solihin, D.D., Sulandari, S., dan Sumantri, C. 2013. Keragaman Fenotipik dan Pendugaan Jarak Genetik pada Ayam Lokal dan Ayam Broiler Menggunakan Analisis Morfologi. Jurnal Veteriner 14(4): 475-484.

Meyliyana, Mugiyono, S., dan Roesdiyanto. 2013. Bobot Badan Berbagai Jenis Ayam Sentul di Gabungan Kelompok Tani Ternak Ciung Wanara Kecamatan Ciamis
Kabupaten Ciamis. Jurnal Ilmiah Peternakan 1(3): 985-992.

Nataamijaya, A.G. 2005. Karakteristik Penampilan Pola Warna Bulu, Kulit, Sisik Kaki, dan Paruh Ayam Pelung di Garut dan Ayam Sentul di Ciamis. Buletin Plasma Nutfah 11(1): $1-5$.

Rangkuti, F. 2001. Analisis SWOT : Teknik Membedah Kasus Bisnis. Gramedia Pustaka Utama. Jakarta. . 2003. Analisis SWOT : Teknik Membedah Kasus Bisnis, Reorientasi, Konsep, Perencanaan Strategis untuk Menghadapi Abad 21. Gramedia Pustaka Utama. Jakarta.

Sartika, T. 2010. Perbandingan Morfometrik Ukuran Tubuh Ayam KUB dan Sentul Melalui Pendekatan Analisis Diskriminan. Seminar Nasional Teknologi Peternakan dan Veteriner 2013. 10 halaman.

Suryana dan Hasbianto, A. 2008. Usaha Tani Ayam Buras di Indonesia: Permasalahan dan Tantangan. Jurnal Litbang Pertanian 27(3): 75-83.

Widjastuti, T. 2009. Pemanfaatan Tepung Daun Pepaya (Carica Papaya.L L Ess) Dalam Upaya Peningkatan Produksi dan Kualitas Telur Ayam Sentul . J. Agroland 16(3): 268 273. 